\title{
Enhancement of the vibration stability of a microdiffraction goniometer
}

\author{
Soon-Hong Lee ${ }^{*}$ Curt Preissner, Barry Lai, Zhonghou Cai, and Deming Shu \\ Advanced Photon Source, Argonne National Laboratory
}

\begin{abstract}
High-precision instrumentation, such as that for x-ray diffraction, electron microscopy, scanning probe microscopy, and other optical micropositioning systems, requires the stability that comes from vibration-isolated support structures. Structure-born vibrations impede the acquisition of accurate experimental data through such highprecision instruments. At the Advanced Photon Source, a multiaxis goniometer is installed in the 2-ID-D station for synchrotron microdiffraction investigations. However, ground vibration can excite the kinematic movements of the goniometer linkages, resulting in critically contaminated experimental data. In this paper, the vibration behavior of the goniometer has been considered. Experimental vibration measurements were conducted to define the present vibration levels and determine the threshold sensitivity of the equipment. In addition, experimental modal tests were conducted and used to guide an analytical finite element analysis. Both results were used for finding the best way to reduce the vibration levels and to develop a vibration damping / isolation structure for the 2-ID-D goniometer. The device that was designed and tested could be used to reduce local vibration levels for the vibration isolation of similar high-precision instruments.
\end{abstract}

Keywords: Vibration, Damping device, Gonoimeter, Viscoelastic materials, Finite element analysis.

\section{INTRODUCTION}

The Advanced Photon Source (APS) is a third-generation synchrotron radiation facility at Argonne National Laboratory. Synchrotron radiation researchers in fields such as materials science, biological science, chemistry, geophysical and planetary sciences, and innovative x-ray instrumentation can use high-brilliance x-ray beams from the APS. Stabilization of the synchrotron x-ray beam by vibration damping and control of storage ring girder assemblies is well researched. ${ }^{1-5}$ In addition, $\mathrm{x}$-ray synchrotron instruments in the experiment stations such as those for x-ray diffraction, electron microscopy, scanning probe microscopy, and other optical micropositioning systems may require additional system stability that comes from vibration-isolated support structures. For synchrotron microdiffraction investigations, a multiaxis goniometer is installed at the APS 2-ID-D experiment station. However, ground vibration and structure-born vibration may excite the kinematic movements of the goniometer linkages and impede the acquisition of accurate experimental data. Thus, the high vibration sensitivity of the equipment may force scientists to discard their experimental data and repeat the experiment. Potential vibration sources at the APS include ambient ground motion, machine activity, or human activities like footfalls in or near the experimental facility.

In this paper, the enhancement of vibration stability for the microdiffraction goniometer through the installation of a viscoelastic damper was considered. To enhance the vibration stability of the goniometer, research on the active precision control of the sample holder using a piezoelectric actuator should be considered for nanometer-level highprecision positioning. But only the damping device will be considered here for reducing the vibratory motion through the stages. Fig. 1 shows a schematic of the goniometer. It consists of three functional parts: the support structures, kinematic moving parts of the central sample holder, and those of the external detector. Kinematic parts for the sample holder consist of phi, kappa, omega, and psi, etc. Parts for the external detector are composed of 2theta and $n u$. The support structure is composed of three subparts: the granite table, supporting frame, and a triad of precision stages. Each stage is composed of a vertical stage and two horizontal sliding and/or fixed stages; triads are referred to as the flat, cone, or v group. Vertical stages can be used to adjust the goniometer height. Each vertical

* slee@aps.anl.gov; phone 1630252 3347; fax 1630252 9350; http://www.aps.anl.gov;

Argonne National Laboratory 9700 S. Cass Avenue, Argonne, IL 60439-4800 
stage is also supported by two horizontal stages that may allow users to adjust horizontal and rotational positions of the goniometer. The horizontal stages are bolted to the welded frame structure that sits on the facility floor. Note that $\mathrm{X}, \mathrm{Y}$, and $\mathrm{Z}$ labels refer to the horizontal direction, $\mathrm{x}$-ray beam direction (transversal direction), and vertical direction, respectively.

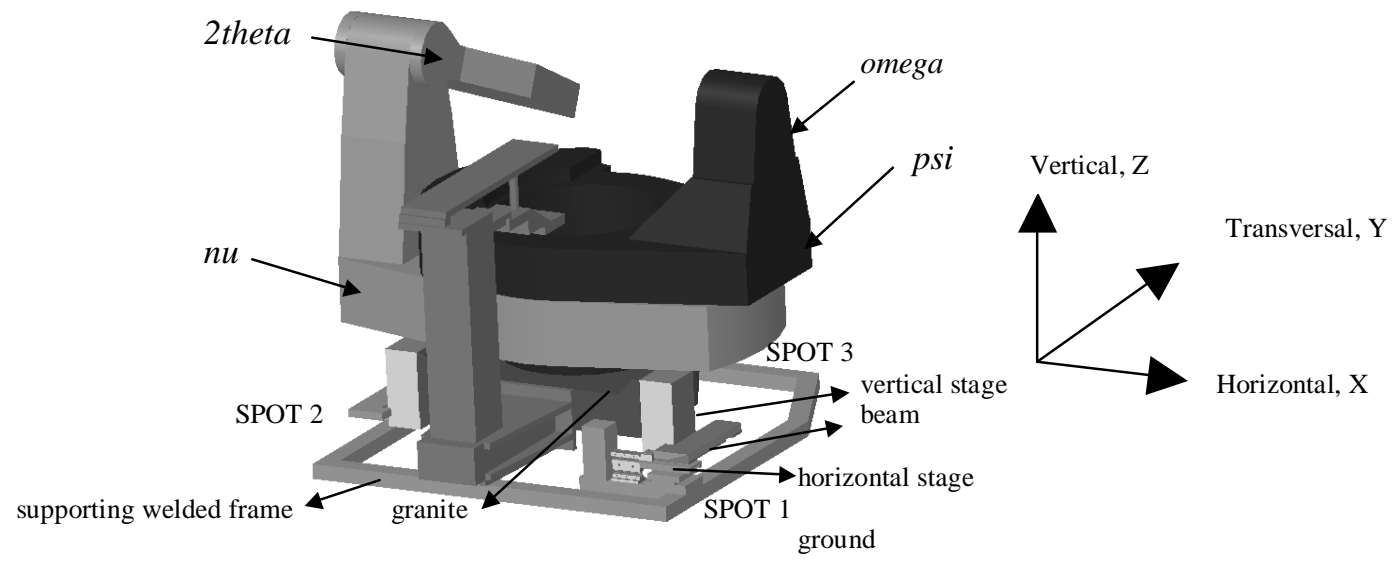

Fig. 1. A schematic of a microdiffraction goniometer ( $k a p p$ and, phi not shown in figure).

\section{VIBRATION MEASUREMENTS AND DYNAMIC SIMULATION ANALYSIS}

\subsection{Experimental vibration measurements}

To enhance the quality of $\mathrm{x}$-ray experimental data from the goniometer, experimental vibration measurements were conducted at several points to define the initial ambient vibration level and to determine the dynamic characteristics of the equipment. In these tests, high-sensitivity, low-frequency piezobased accelerometers (VibroMetrics Model 1030), a 16 channel HP-VXI system, and a SignalCalc 620 (Data Physics) or a HP35667 dynamic analyzer were used to measure vertical, transverse, and horizontal accelerations in the frequency domain. During these measurements operating conditions were maintained, no foot traffic took place in the station, and only an electric controller fan was on. Results of autopower spectrum measurements up to $100 \mathrm{~Hz}$ are shown in Fig. 2 (a-b). In the figures, the solid straight line represents $50 \mathrm{~nm}(\mathrm{rms})$, which the scientists want to achieve throughout the frequency range. In Fig. 2(a), clearly, horizontal motion is dominant around $6 \sim 9 \mathrm{~Hz}$ with peak magnitudes of $70 \sim 170 \mathrm{~nm}$ (rms). It is also evident that vibration motion at the center table shows the same level as the top of granite table. Note that the granite table is directly connected to the center table and that ground level means the welded frame sitting on the floor and supporting the horizontal stages. Within these tests, the sample stage, which is connected to the kappa stage, has peaks of $90 \mathrm{~nm}$ at $8 \mathrm{~Hz}$ and $15 \sim 20 \mathrm{~Hz}$. Horizontal sliding stages might be suspected to add to the horizontal vibration motion. In Fig. 2(b), vertical motion exhibits significant resonant peaks around $20 \mathrm{~Hz}$. Not shown in this paper, the beam direction vibratory motion was almost the same as the horizontal vibratory motion. The largest vibration peak observed in the beam direction was at $20 \mathrm{~Hz}$ with a $270 \mathrm{~nm}$ (rms) amplitude, which might result from the kinematic movement of the kappa linkage. Common to all measurements was the $53 \mathrm{~Hz}$ peak due to the electric fan for the motor control electronics and low floor vibration motions below $10 \mathrm{~nm}$.

As shown in Fig. 2, there are many peaks in the frequency range of 6 to $9 \mathrm{~Hz}$. Experimental modal tests were conducted to determine the motion of these modes and subsequently used to guide the analytical finite element analyses. Impact hammer excitation along with a ME'Scope was used to perform the modal tests. Table 1 displays the modal information. The first mode of interest was horizontal motion at the natural frequency of $7.75 \mathrm{~Hz}$ and with $9.86 \%$ damping coefficient. The second mode was at $9.63 \mathrm{~Hz}$ and the third mode was at $15.3 \mathrm{~Hz}$.

Furthermore, transmissibility measurements were made, a measure of the reduction of transmitted force or motion afforded by an isolator. To evaluate this transmissibility, the relative motion between two points within each stage triad was measured. This was done at each corner (spot) of the goniometer. Fig. 3 represents the transmissibility of vibration motions at (a) SPOT 1 and (b) SPOT 3. Here, X1 represents a measurement point of the welded frame structure on which the horizontal stages are supported. 


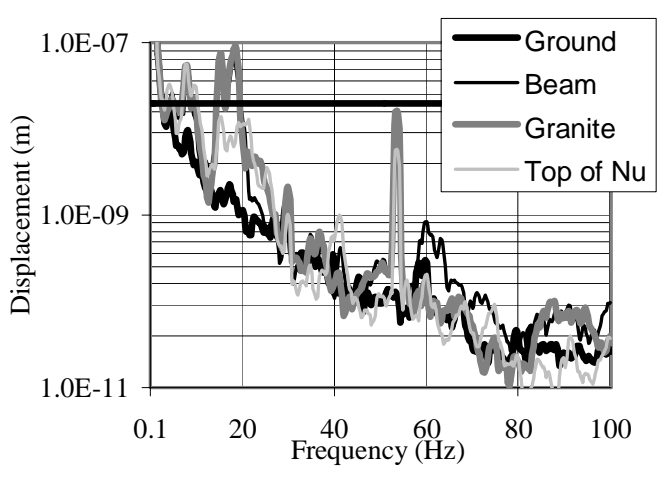

(a) Horizontal motion



(b) Vertical motion

Fig. 2. Autopower spectrum measurement results (figure captions refer to Fig. 1).

$\mathrm{X} 2$ represents a measurement point on a supporting beam that is supported by the horizontal stages. $\mathrm{X} 3$ is a measurement point on the granite table that is supported by the vertical stages. Here, $\mathrm{X}$ represents the horizontal direction and $\mathrm{Z}$ represents the vertical direction. For example, $\mathrm{X} 1 \mathrm{X} 2$ represents horizontal transmissibility between the supporting welded frame and the beam on the horizontal stage. As shown in Fig. 3, transmissibility (X1X3) between the supporting welded frame and the granite table displayed the largest peak at a frequency of 25. Fig. 3(a) showed the transmissibility values are of $7 \sim 10$ at the frequencies of 7, 15, and $18 \mathrm{~Hz}$. In addition, the horizontal transmissibility (X1X3) between the supporting welded frame and the granite has almost the same level as with $\mathrm{X} 1 \mathrm{X} 2$ between the supporting welded frame and the beam on the horizontal stage. This means that the vertical stages supported on the beam have not had much contribution to the horizontal motion amplification from the supporting welded frame to the granite. Hence, both vertical transmissibilities showed pretty low in the frequency range below $20 \mathrm{~Hz}$. It means the stages are well damped vertically in this frequency range at both SPOTs. From the experimental data, the horizontal stages largely contribute to the horizontal vibratory motion of the goniometer, especially, in the low frequency range of $6 \sim 9 \mathrm{~Hz}$, which was also confirmed through the transmissibility tests. Therefore, in this study, the main objective is to reduce the vibration level using a damping device in the frequency range of $6 \sim 9 \mathrm{~Hz}$.



(a) SPOT 1

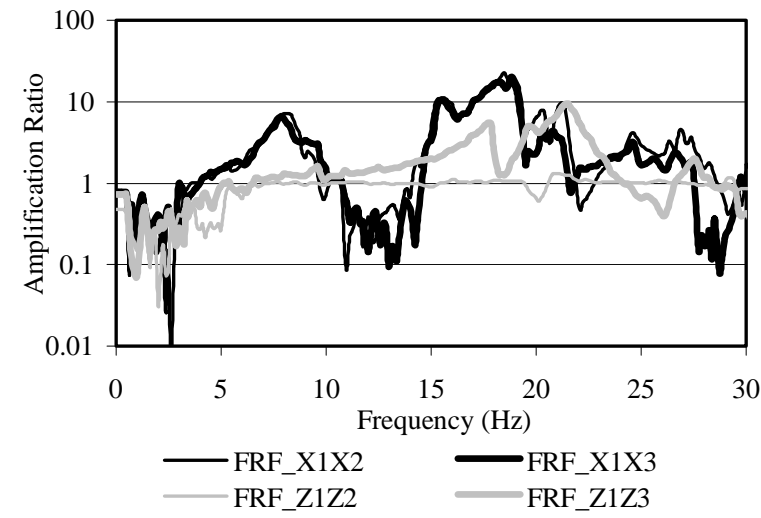

(b) SPOT 3

Fig. 3. Typical vibration amplification ratio of a goniometer.

\subsection{Dynamic simulation analysis}

Based on the experimental test results, an analytical finite element model of a goniometer was built on the ANSYS platform based on the spring stiffness and damping coefficients of various stages, as determined from prior research. ${ }^{6-8}$ Fig. 4 shows a lumped mass finite element model that was simplified from the real structure by consolidating the complex structure above the granite. Modal analyses and harmonic analyses were carried out. Table 1 shows the first 5 natural frequencies of the goniometer through numerical modal analysis with/without spring-damper elements. 

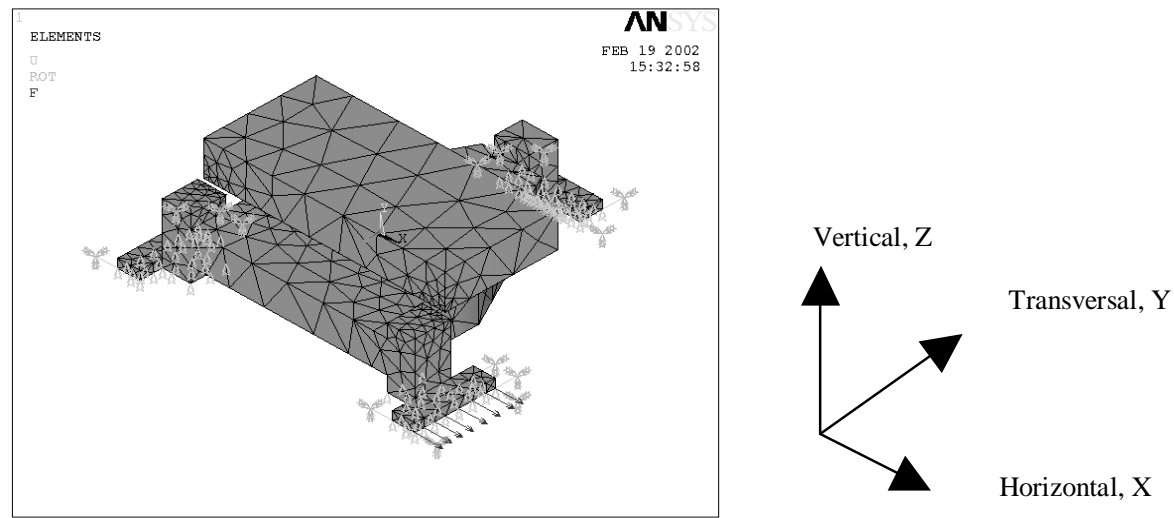

Fig. 4. Analytical finite element model for the goniometer.

Table 1. Modal tests and modal analysis results.

\begin{tabular}{|c|c|c|c|c|c|c|}
\hline \multirow{2}{*}{ Mode } & \multicolumn{2}{|c|}{ Without Damper } & \multicolumn{4}{c|}{ With Damper by ANSYS } \\
\cline { 2 - 6 } & Experimental & ANSYS & $\begin{array}{c}\text { Low } \\
\text { stiffness }\end{array}$ & $\begin{array}{c}\text { High stiffness } \\
\text { (Spot 1 only) }\end{array}$ & $\begin{array}{c}2 \text { high stiffness } \\
\text { (Spot 1, 3) }\end{array}$ & Mode \\
\hline 1 & $6 \sim 9(7.75)$ & 6.765 & 6.872 & 7.659 & 8.928 & X - translation \\
\hline 2 & $9 \sim 11(9.63)$ & 9.610 & 9.613 & 9.643 & 9.651 & Y- translation \\
\hline 3 & $14 \sim 18(15.9)$ & 18.73 & 18.83 & 19.69 & 21.16 & Z - rotation \\
\hline 4 & & 134.9 & 134.9 & 134.9 & 135.2 & Flexible modes \\
\hline 5 & & 155.1 & 155.1 & 155.2 & 155.8 & \\
\hline
\end{tabular}

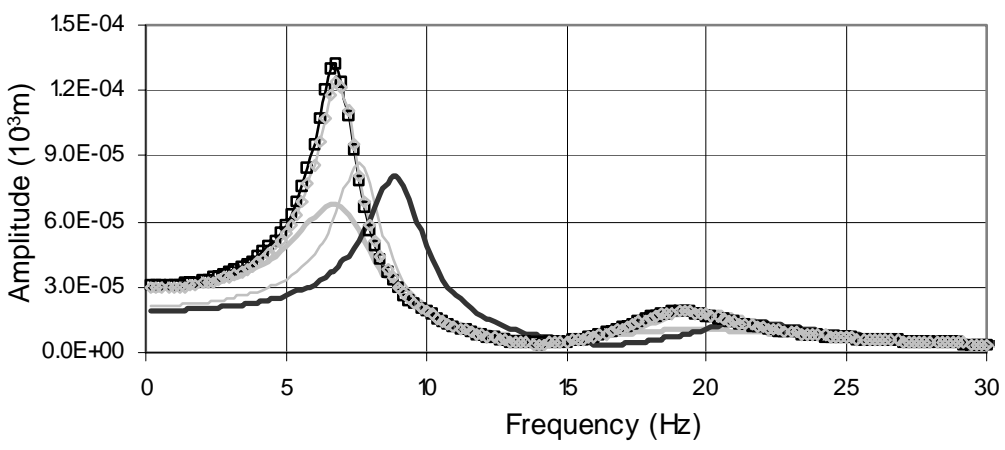

$\longrightarrow$ Without Damper (System Damping 9.86\%)
Without Damper (System Damping 20\%)
High Stiffness Damper (K=1 e6 N/m, C=20\%)
- Low Stiffness Damper (K=1 e5 N/m, C=20\%)
2 High stiffness Dampers $(\mathrm{K}=1 \mathrm{e} 6 \mathrm{~N} / \mathrm{m}, \mathrm{C}=20 \%)$

Fig. 5. Results of harmonic analysis.

Fig. 5 shows the harmonic simulation results with various stiffness values and damping factors that have been used for the previous evaluations of stages at the APS. ${ }^{6-8}$ Analytical simulation results show that, to achieve a $40 \%$ amplitude reduction, it may be necessary to apply a damping device with an over $20 \%$ damping coefficient and over $1 \mathrm{e} 6 \mathrm{~N} / \mathrm{m}$ of spring stiffness. Based on the experimental tests and analytical simulations, a damping device may be designed to have minimum spring stiffness of $1 \mathrm{E} 6 \mathrm{~N} / \mathrm{m}$ and at least a $20 \%$ damping ratio (loss factor $=0.4$ ) to achieve the desired vibratory response motion of $50 \mathrm{~nm}(\mathrm{rms})$ at the $\mathrm{x}$-ray experimental sample holder. 


\section{DESIGN OF DAMPING DEVICE}

\subsection{Basic design concepts}

In order to match the minimum design specifications on spring stiffness and damping ratio, the following concepts were applied in designing a damping device.

1. Viscoelastic damping material (VEM) - low cost, wide frequency range - will be used.

2. Horizontal vibration motion of stage causes shearing strain in VEM.

3. Shear strain energy stored in VEM will be dissipated by heat.

4. Structure should have horizontally strong and transversally weak link

- $\quad$ To provide sufficient horizontal stiffness

- $\quad$ To decouple transverse motion

- $\quad$ To maximize VEM damping loss by adjusting transversal clamping force to VEM assembly.

\subsection{Design process}

The following steps were applied for damping device design.

1. Vibration measurements

2. Theoretical analyses and simulation for design

- $\quad$ Survey for size of damping device - Find available space and device dimension

- $\quad$ Modal and harmonic analyses using ANSYS to extract design parameters

- $\quad$ Determine layer thickness and VEM thickness

- $\quad$ Damping mechanism analysis

3. Prototype damping device built

4. Experimental verification of designed prototype damping device

5. Optimization of the damping device

6. Mock-up tests with optimal damping device and its evaluation

7. Implementation of damping device to the real application

- Performance tests before and after installation of damping device

\subsection{Damping mechanism design}

There are many ways to define the damping of a system. For proper understanding, it is imperative to understand how the different metrics are related. Many terminologies are used to define their damping characteristics. The loss factor represents the relationship between the sinusoidal excitation of a system and the corresponding sinusoidal response. In the synchrotron $\mathrm{x}$-ray instrumentation application, the quality factor $(\mathrm{Q})$ is typically used to evaluate the effectiveness of damping device. ${ }^{1-5}$ Table 2 shows the comparison of damping measures that are used to define the damping of a system. ${ }^{9}$

Table 2. Summary of damping terminology

\begin{tabular}{|c|c|}
\hline Quality or magnification factor, Q & $\mathbf{Q}=\frac{1}{\boldsymbol{\eta}}=\frac{\mathbf{1}}{\mathbf{2} \zeta}$ \\
\hline Viscous damping ratio (\% of critical damping) & $\zeta=\frac{\mathbf{c}}{2 \mathbf{m} \omega_{\mathbf{n}}}=\frac{\mathbf{c}}{\mathbf{c}_{\mathbf{c}}}$ \\
\hline Loss factor, (Loss tangent) & $\boldsymbol{\eta}=\tan \boldsymbol{\delta}=\frac{\mathbf{G}^{\prime \prime}}{\mathbf{G}^{\prime}}$ \\
\hline
\end{tabular}

There are many applications using VEMs to suppress vibratory motions. ${ }^{10}{ }^{15}$ To find the proper VEMs for our specific application, data on possible VEMs used for damping applications in x-ray facilities are shown in Table 3. From this table, damping materials were elected. Based on the allowed space for device installation, we can decide the size of the VEM and then size of the liners. For the VEM, 3M 468MP was chosen because this material has already been used for the vibration suppression of storage ring girder motion at the APS. It has been subjected to radiation tests, creep tests, and aging tests, thus its material behavior in an x-ray environment is well quantified. Note that creep may not be critical in this application. Table 4 shows the typical damping characteristics of $3 \mathrm{M}$ 
468MP. Technical data such as loss factor and shear modulus at the specific frequencies of $0.3 \mathrm{~Hz}, 3 \mathrm{~Hz}$, and $30 \mathrm{~Hz}$ were supplied from 3M. This material's shear modulus and loss factor are dependent on the frequency and the temperature. Temperature does not need to be considered in this application because the use of the damper will be restricted to the well-conditioned experiment station. However, as damping loss proceeds, the energy damped will be converted to heat energy and then will increase the temperature of device. But, it varies less $6^{\circ} \mathrm{F}$, which does not affect the damping loss critically. Also, we used only one thickness dimension for liners. To increase the stiffness and also to allow a motion along the lateral direction, a weak-link mechanism was adopted along the horizontal direction. Using these basic design factors, modal analyses and structural analyses were conducted in order to optimize the thickness and the size of the liner and the groove thickness for the weak link, etc. Based on the simulation results, the basic dimensions of the VEM and liners with weak-link grooves were decided.

Table 3. Examples of VEM damping applications at x-ray facilities.

\begin{tabular}{|c|c|c|c|c|c|}
\hline \multirow{3}{*}{\multicolumn{2}{|c|}{ APS }} & VEM & Liner & Damping effects & Remarks \\
\hline & & $\begin{array}{c}\text { ISD } 3128 \\
\text { (12"x8.5"x0.004 } \\
\sim 0.016 ") \\
\text { 2 layers } \\
\end{array}$ & $\begin{array}{l}\text { Stainless } 1 / 8 ” \\
(3.175 \mathrm{~mm})\end{array}$ & Q factor: 61 to 5 & $\begin{array}{l}\text { Tested ISD } 112,465,468, \\
3127,3128 \text {. } \\
\text { Seated between wedge jack } \\
\text { and pedestal }\end{array}$ \\
\hline & & $\begin{array}{l}\text { Anatrol } 217 \\
(12 ” \times 8.5 " \\
\text { x } 0.006 ") \\
2 \text { layers }\end{array}$ & $\begin{array}{l}\text { Stainless } 1 / 16 " \\
(1.5875 \mathrm{~mm})\end{array}$ & Q factor: 100 to 10 & $\begin{array}{l}\text { PSD level }\left(2.3 \mathrm{e} 5 \mathrm{~nm}^{2} / \mathrm{Hz}->\right. \\
\left.2.3 \mathrm{e} 4 \mathrm{~nm}^{2} / \mathrm{Hz}\right) \\
\text { Tested pedestal stiffness } \\
\text { effects. }\end{array}$ \\
\hline \multirow{6}{*}{$\begin{array}{l}\mathrm{E} \\
\mathrm{S} \\
\mathrm{R} \\
\mathrm{F}\end{array}$} & \multirow{5}{*}{$\begin{array}{l}\text { Damping } \\
\text { Plate }\end{array}$} & $\begin{array}{l}\text { AN217 } 2 \text { layers } \\
\text { (APS supplied) }\end{array}$ & - & $\begin{array}{c}\text { Q factor: } 48.78 \text { to } 34.55 \\
(8.38 \mathrm{~Hz})\end{array}$ & \multirow{5}{*}{$\begin{array}{l}\text { Damping plate position drift } \\
\text { reaches } 600 \text { um at } I=200 \mathrm{~mA} \\
\text { possibly due to the thermal } \\
\text { deformation of the vacuum } \\
\text { chamber and the weak shear } \\
\text { stiffness of the damping } \\
\text { plate. }\end{array}$} \\
\hline & & $\begin{array}{l}\text { AN190 } 2 \text { layers } \\
\text { (Each } 0.25 \mathrm{~mm})\end{array}$ & $2 \mathrm{~mm}$ liner & Q factor: to 11.51 & \\
\hline & & $\begin{array}{l}\text { AN217 } 2 \text { layers } \\
\text { (Each } 0.25 \mathrm{~mm})\end{array}$ & $2 \mathrm{~mm}$ liner & $\begin{array}{l}\text { Q factor: to } 9.36 \text { (bolt), } \\
\text { to } 9.35 \text { (unbolt) }\end{array}$ & \\
\hline & & $\begin{array}{l}\text { FD220 } 2 \text { layers } \\
\text { (Each } 0.25 \mathrm{~mm} \text { ) }\end{array}$ & $2 \mathrm{~mm}$ liner & $\begin{array}{l}\text { Q factor: to } 8.99 \text { (bolt), } \\
\text { to } 7.04 \text { (unbolt), } \\
\text { to } 4.68 \text { (glue) }\end{array}$ & \\
\hline & & $\begin{array}{l}\text { FD220 } 6 \text { layers } \\
\text { (Each } 0.16 \mathrm{~mm} \text { ) }\end{array}$ & $\begin{array}{l}2 \mathrm{~mm} \text { end liner and } \\
0.5 \mathrm{~mm} \text { thin liners }\end{array}$ & $\begin{array}{c}\mathrm{Q} \text { factor: to } 14.16 \text { (bolt), } \\
\text { to } 7.0 \text { (unbolt), } \\
\text { to } 4.96 \text { (glue) }\end{array}$ & \\
\hline & $\begin{array}{l}\text { Damping } \\
\text { Link }\end{array}$ & RT106 & $\begin{array}{l}\text { Loss factor }=0.62, \\
\text { Young's modulus } \\
\text { E=12MPa }\end{array}$ & Q factor: $40 \sim 60$ to $6 \sim 10$ & $\begin{array}{l}\text { Damping Link has more } \\
\text { damping effects than } \\
\text { damping plates. }\end{array}$ \\
\hline
\end{tabular}

Table 4. Typical shear modulus and loss factor based on $3 \mathrm{M} 468 \mathrm{MP}$ technical data (ambient temperature $25^{\circ} \mathrm{C}$ )

\begin{tabular}{|c|c|c|c|c|}
\hline \multirow{2}{*}{ Frequency } & \multirow{2}{*}{$\log \mathrm{G}^{*}$} & \multirow{2}{*}{$\log \mathrm{G}^{\prime}}$, & \multicolumn{2}{|c|}{$\eta=\tan \boldsymbol{\delta}=\frac{\boldsymbol{G}^{\prime}}{\boldsymbol{G}^{\prime \prime}}$} \\
\cline { 4 - 5 } & & & Calculation & 3M Graphs \\
\hline $30 \mathrm{~Hz}$ & 6.05 & 6.1 & 1.13 & 1.15 \\
\hline $3 \mathrm{~Hz}$ & 5.52 & 5.52 & 1.01 & 1.02 \\
\hline $0.3 \mathrm{~Hz}$ & 5.15 & 5.0 & 0.71 & 0.75 \\
\hline
\end{tabular}

After designing the components for the damping device, the most important step is to bond the VEMs to the liners. If not well bonded between the liners, insufficient damping would result. For acceptable bonding of the 3M VEM, it is necessary for the surfaces to be dry and free of any wax, grease, dust, dirt, oil or any other contaminants. Therefore, the liner surfaces must be chemically etched or cleaned with solvents like isopropyl alcohol or heptane. 
To make an adequate bond to a contamination-free surface and to avoid air entrapment, only rolling or squeegeeing methods can be applied to the liner surfaces. An assembly jig was used for the VEM laid on the surface of each liner. That is, the VEM was bonded between upper and lower liners. The upper liners can be bolted to the upper fixture, and the lower liners bolted to the lower fixture. To compensate the thickness of the VEM between upper liners (or lower liners) and upper fixture (or lower fixture), three 0.0015 " aluminum foil shims were inserted.

The damping mechanism can be explained as follows: any horizontal stage motion across the damping device will move the upper fixture and upper liners with respect to the lower fixture and lower liners. The lower liner movement is constrained by a bolted joint to the supporting welded frame. The relative movement results in shear strain within the VEM separating the upper and lower liners, and as the VEM returns to the unstrained state, stored strain energy is dissipated as heat, thereby damping the goniometer motion.

In summary, a damping device that can be characterized as a passive damper with multilayered VEM has been developed. To maximize the damping performance, each liner has weak-link grooves that allow it to move transversely and that make it possible to increase the VEM shearing force by tightening bolts and nuts with cover plates. The damping device as designed is shown in Fig. 6.

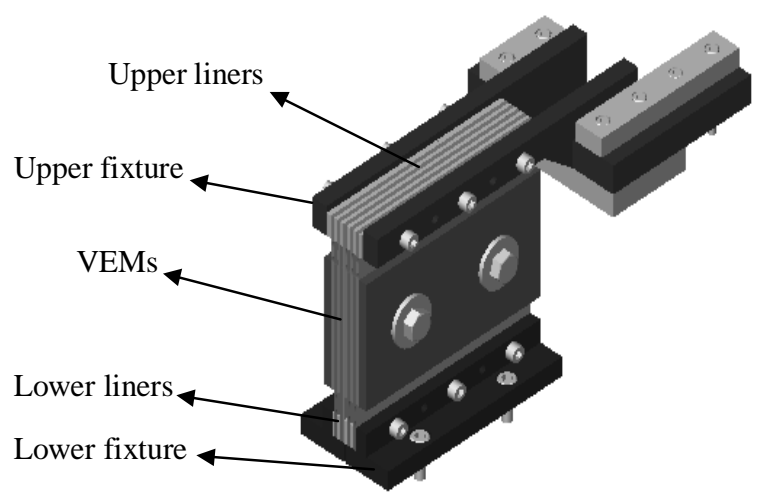

Fig. 6. Prototype damping device.

\section{PERFORMANCE TEST RESULTS}

To verify the performance of the damping device, dynamic complex stiffness tests were carried out. Dynamic complex stiffness and loss factors can be determined from the complex compliance frequency response function., ${ }^{6-}$

${ }^{16}$ The reciprocal of the complex compliance function is the complex stiffness function that represents force per unit displacement through the frequency range of interest. The real component of the complex stiffness function indicates the dynamic stiffness, and the imaginary component represents the phase lag that is comparable to the damping. The loss factor can be obtained by the imaginary part divided by the real component of the complex stiffness function. For the measurement of force and motion, an impedance head and B\&K shaker, two accelerometers, a Signal Calc 620, and a VXI data acquisition system were used. Using the HP35665A dynamic analyzer, a $0 \sim 50 \mathrm{~Hz}$ random excitation signal was generated and applied to the shaker, and both the input force and output accelerometer signals from the damper were filtered using a Hanning window. The schematic test setup on optical table is shown in Fig. 7. Complex stiffness of the device was measured as the force/motion frequency response function as shown in Fig. 8. Due to optical table motion in the test setup, there are peaks in the random stiffness test results below $10 \mathrm{~Hz}$. So, to estimate in this range of frequency, sinusoidal signals of 1,5,10, and $20 \mathrm{~Hz}$ were input to the shaker, and the stiffness values were extracted and then were curve fitted. As was simulated, the stiffness is over $1 \mathrm{e} 6 \mathrm{~N} / \mathrm{m}$ at the whole range of frequency except below $10 \mathrm{~Hz}$ that is a little bit less that $1 \mathrm{e} 6 \mathrm{~N} / \mathrm{m}$. After lab tests of the damping device, we have installed it on the goniometer during a beam shut down at the APS. Before installation, the vibratory motion was measured without the damper to measure the effectiveness of the damper. After installation, vibratory motion was measured without torqueing the clamping bolts. One more measurement was conducted to estimate the effects of applied clamping torque. The damping device was initially designed for possible adjustment of the damping loss according to the pressure applied by cover plates due to 
tightening torque. Fig. 9 shows on-site test results without/with damper and without/with clamping load. Test results show that the damping device is effective to damp and shift upward the vibratory motion in the frequency range of 6-16 Hz, especially along the horizontal direction. Peaks at $7 \mathrm{~Hz}$ and $14 \mathrm{~Hz}$ were damped down and shifted upward to $10 \mathrm{~Hz}$ and $17 \mathrm{~Hz}$, respectively. However, the vertical direction experienced no effects. Fig. 10 shows horizontal and vertical transmissibility between the ground and the granite. Results showed that horizontal amplification ratio was 9.65 at $7.88 \mathrm{~Hz}$ before the installation of a damping device, and that changed to $6.45 \mathrm{at} 10 \mathrm{~Hz}$ after installing the damping device. The damping device can effectively damp down the horizontal vibratory motion at the granite by over $33 \%$. Although it was expected to observe dependence of damper performance on clamping load, no such dependence was indicated in the results.

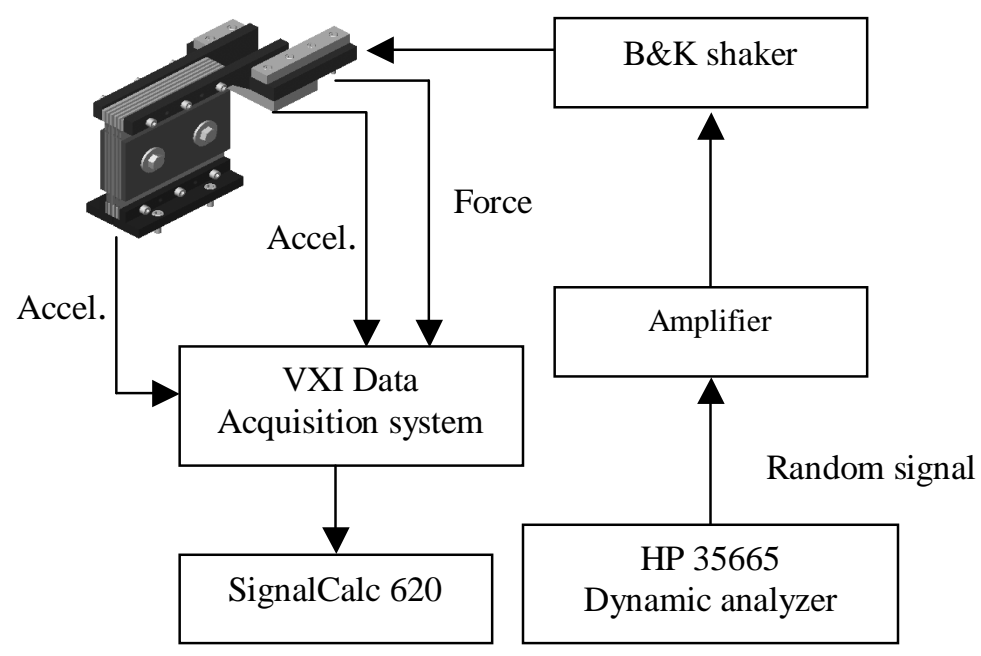

Fig. 7. A schematic diagram of the dynamic complex stiffness test.



Fig. 8. Dynamic stiffness of the damping device 


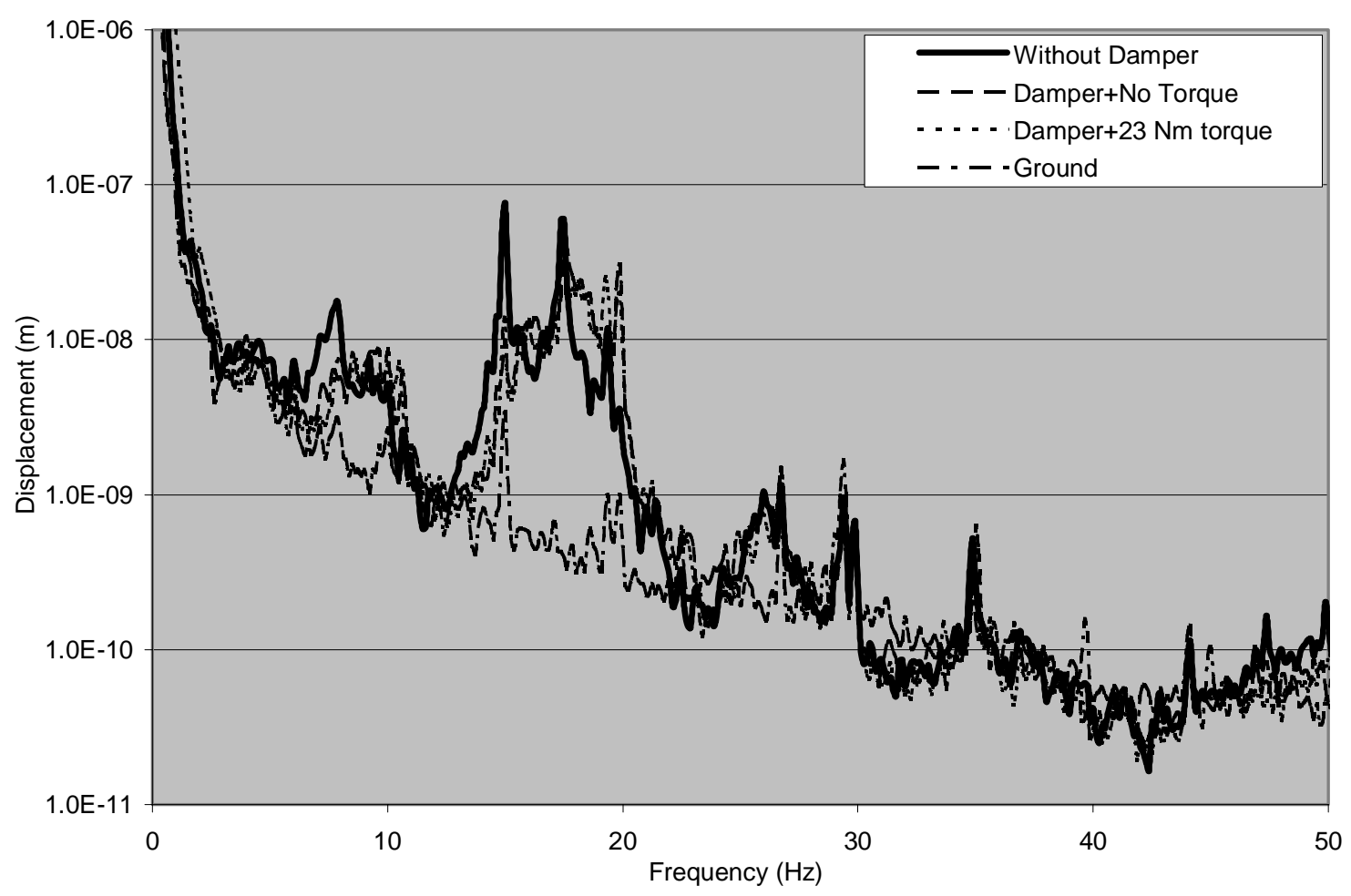

(a) Horizontal motion

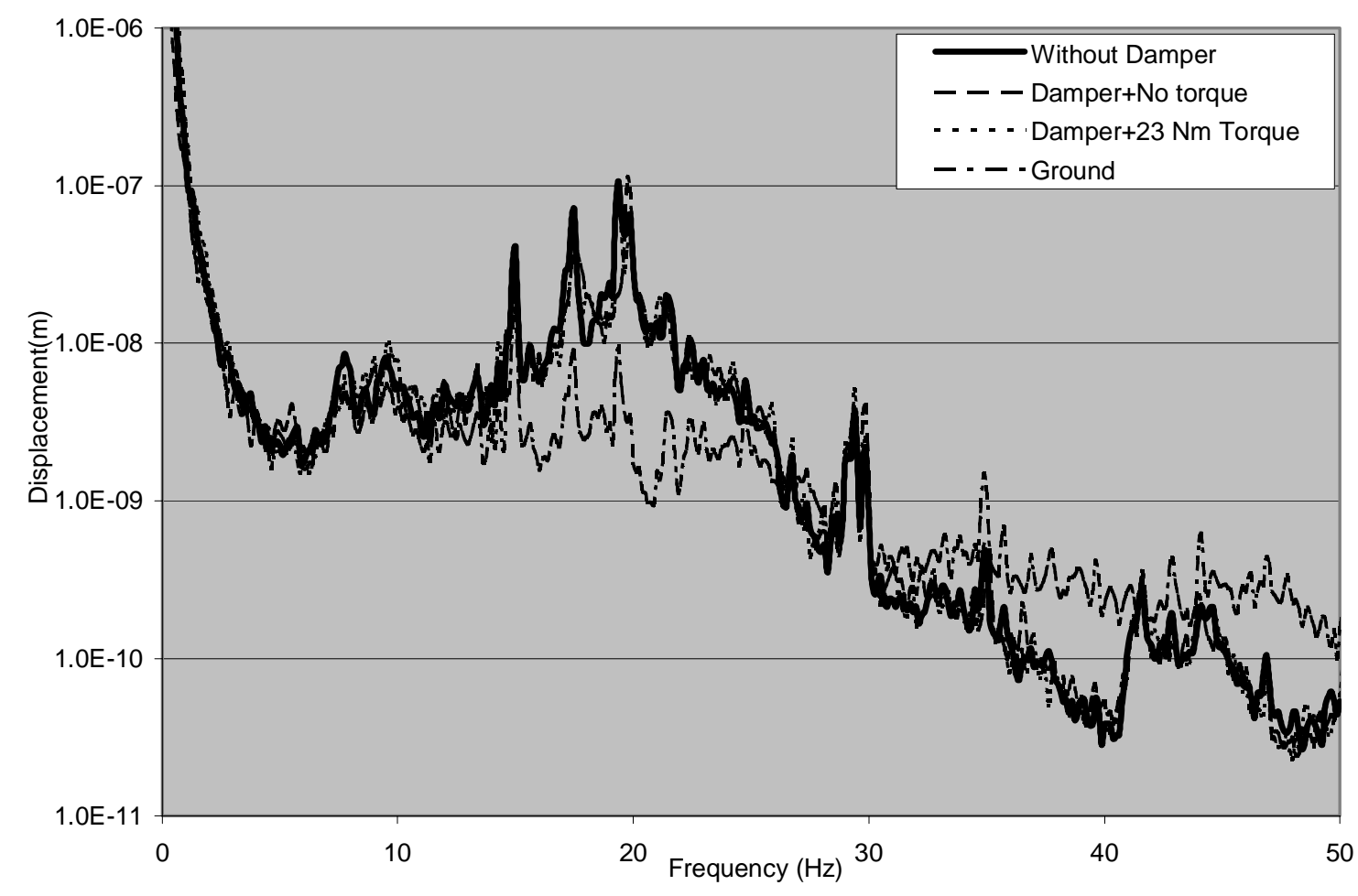

(b) Vertical motion

Fig. 9. Comparison of vibratory motion before/after installation of the damping device. 


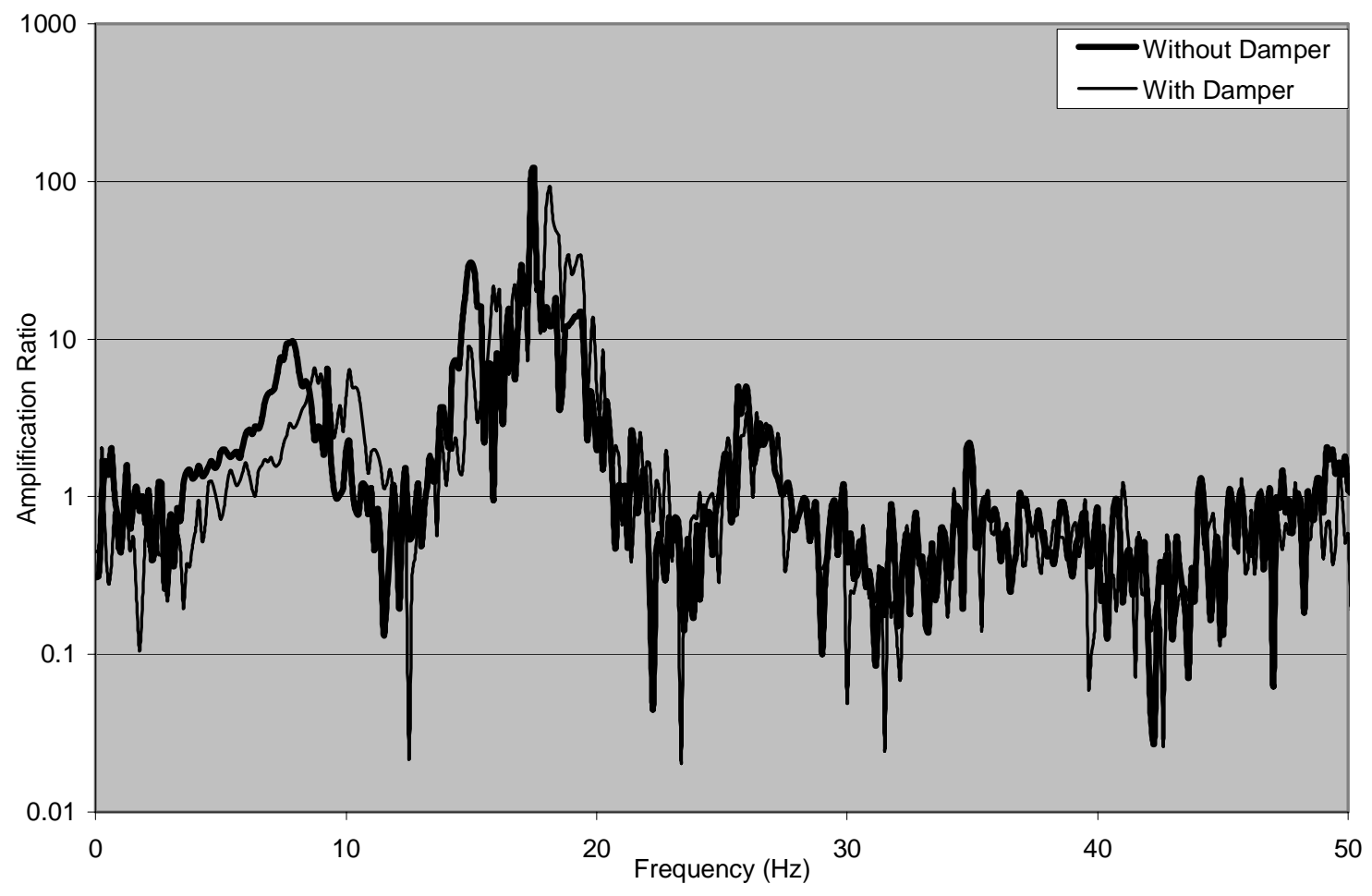

(a) Horizontal direction

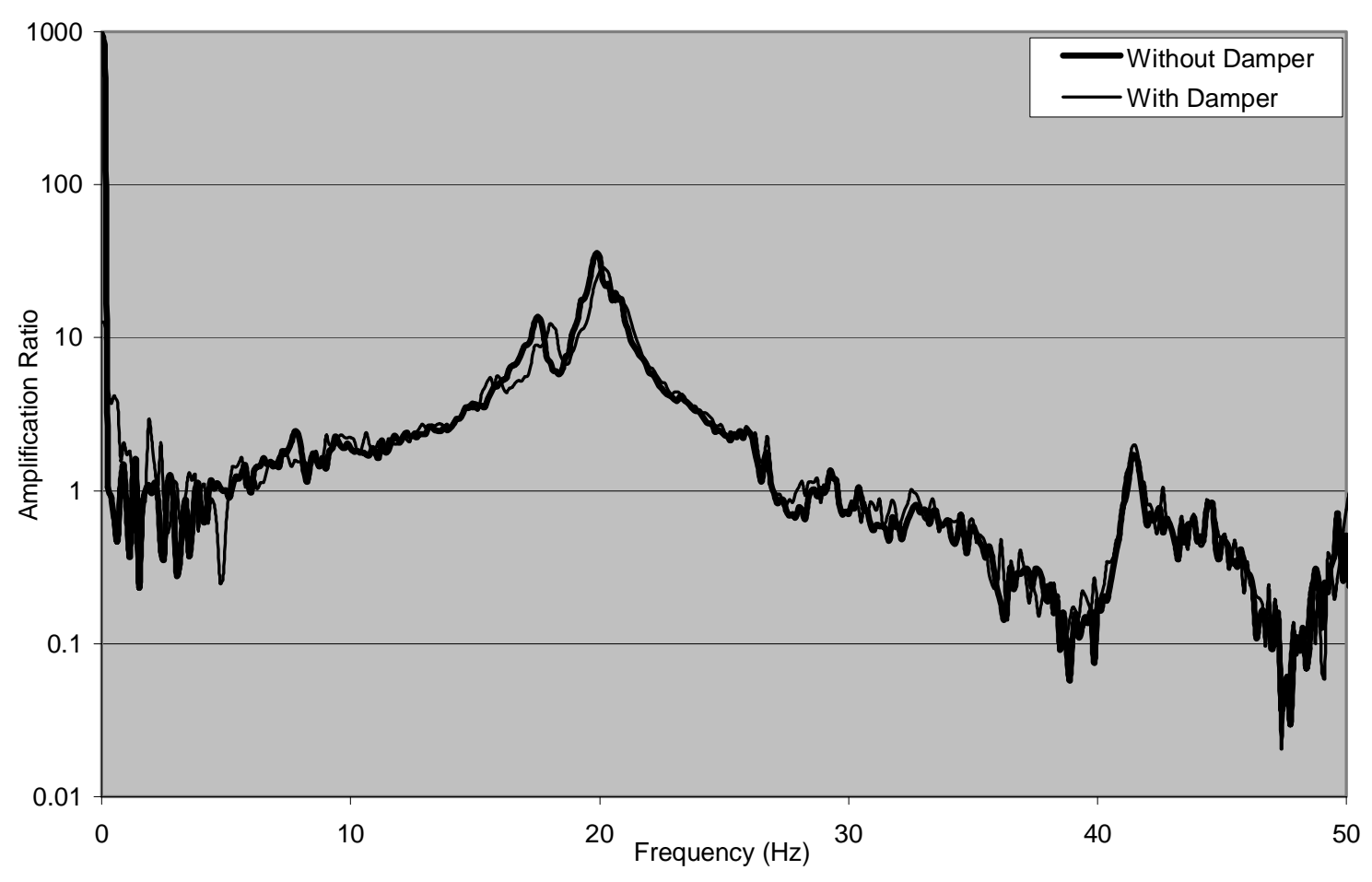

(b) Vertical direction

Fig. 10. Vibration amplification ratio of a goniometer with/without the damper 


\section{CONCLUSIONS}

A damping device was designed for the suppression of vibratory motion in the application of a microdiffraction goniometer. The damper was installed at the horizontal stage and resulted in a 33\% reduction of horizontal vibratory response of the granite table as compared to the goniometer without the device. In addition, horizontal natural frequencies were shifted upward from $7 \mathrm{~Hz}$ to $10 \mathrm{~Hz}$ and $14 \mathrm{~Hz}$ to $17 \mathrm{~Hz}$ with a corresponding reduction in amplitude. These experimental results are well matched with the results predicted by the finite element model. The device did not effectively damp the vertical vibratory motion. Another damper for the vertical directional motion may be needed. Research on the active precision control of the sample holder using a piezoelectric actuator may be also required for nanometer-level high-precision positioning.

The device with viscoelastic materials evaluated in this paper provides the capability for the suppression of horizontal vibration motion at low frequencies in high-precision instruments. It was successfully installed to increase vibration damping and to reduce the vibratory response for the microdiffraction goniometer of 2-ID-D station at the APS. This device could be useful for reducing local vibration levels for similar high-precision instruments.

\section{ACKNOWLEDGMENTS}

Work supported by the U.S. Department of Energy, Office of Basic Energy Science, under contract No. W-31-109ENG-38.

\section{REFERENCES}

1. D. Magna, S. Sharma, and J. Jendrzejczyk, "Passive vibration damping of the APS machine components," ANL Report ANL/ASD/CP_88981, 1995.

2. C. Ader, J Jendrzejczyk, and D. Mangra, "The application of viscoelastic damping materials to control the vibration of magnets in a synchrotron radiation facility," ANL Report ANL/ET/CP-85273, 1995.

3. D. Magna, S. Sharma, and C Doose, "Performance of the vibration damping pads in the APS storage ring," $1^{s t}$ International Workshop on Mechanical Engineering Design of Synchrotron Radiation Equipment and Instruments, Paul Scherrer Institute, Wurenlingen/Villigen, Switzerland, July 13/14, 2000.

4. L. Zhang, "Damping link to attenuate vibrations of magnet girder assemblies," ESRF Newsletter, p41-43, June 2001.

5. L. Zhang, "Vibration damping device development for the ESRF storage ring Magnet girder assemblies," $22^{\text {nd }}$ Advanced ICFA Beam Dynamics Workshop on Ground Motion in Future Accelerators, November 6-9, 2000, Stanford, CA.

6. I. Basdogan, "A theoretical and experimental study of the dynamic response of high precision optical positioning systems," Ph.D. Dissertation, Department of Mechanical Engineering, University of Illinois at Chicago, 1997.

7. J. Barraza, "Vibratory response modeling and verification of a high precision optical positioning system," M.S. Thesis, Department of Mechanical Engineering, University of Illinois at Chicago, 1999.

8. T. J. Royston and I. Basdogan, "Vibration transmission through self-aligning (spherical rolling element bearings: Theory and experiment." Journal of Sound and Vibration 215(5), 997-1014, 1998.

9. Cyril M. Harris, Shock and Vibration Handbook, $4^{\text {th }}$ edition (McGraw Hill, New York, 1996).

10. P. S. Wilke, T. A. Decker, and L. C. Hale, "Highly-damped exactly-constrained mounting of an x-ray telescope," Smart Structures and Materials 1995:Passive Damping, Proc. SPIE 2445, 2-13, 1995.

11. D. Nashif, D. I. G. Jones, and J. P. Henderson, Vibration Damping (John Wiley \& Sons, New York, 1985).

12. H. Park and A. Baz, "Vibration damping and control using active constrained layer damping: A survey," The Shock and Vibration Digest, 31(5), 355-364, 1999.

13. A. R. Johnson, "Modeling viscoelastic materials using internal variables," The Shock and Vibration Digest, 31(2), 91-100, 1999.

14. R. E. Holman, S. M. Spencer, E. M. Austin, and C. D. Johnson, "Passive damping technology demonstration," Smart Structures and Materials 1995:Passive Damping, Proc. SPIE 2445, 14-27, 1995.

15. J. R. Maly, S.C. Pendleton, J. Salmanoff, G. L Blount, and K. Mathews, "Hubble space telescope solar array damper," Journal of the Institute of Environmental Sciences, XL(5), 35-44, 1997.

16. T.J. Royston, "Vibration characteristics of an APS lab facility in building 401," ANL Report APS/LS Note 263, 1996. 